\title{
DEL PAPEL A LA PANTALLA: ALGUNAS REFLEXIONES SOBRE LA MIGRACIÓN DE LAS LETRAS
}

\author{
Andrea Meza Navarro \\ Universidad Tecnológica Metropolitana \\ macameza@gmail.com
}

\begin{abstract}
"En un pueblo de Escocia venden libros con una página en blanco perdida en algún lugar del volumen. Si un lector desemboca en esa página al dar las tres de la tarde, muere".
\end{abstract}

Julio Cortázar. Página asesina

No todos los libros que visualizamos en una pantalla permiten el mismo ejercicio de interacción, la experiencia varía también de un dispositivo a otro. Existen formatos digitales como el ePub y el AZW, donde el lector tiene el control y el poder de elegir el tipo de letra, su tamaño, el color del fondo, entre otros aspectos que tienen relación con la visualidad de la escritura. Son formatos que permiten la maquetación ajustable, en donde el texto no es estático, fluye como las ideas que despierta, se adapta al tamaño del aparato involucrado en la lectura y lo que es más importante, se adapta a su lector ¿Hemos pensado lo que eso significa? ¿Es un gesto natural, simple y banal? Yo aquí invito a reflexionar sobre esta cuestión que me parece trascendental, intentando visualizar los nuevos roles y atribuciones del lector en el hacer del texto y su consumo.

"Las letras no son signos para los sonidos hablados espontáneamente, sino para los sonidos emitidos por convención, y las reglas de la escritura no son las reglas del hablar, sino que ellas han sido derivadas y perfeccionadas a partir de estas reglas" nos recuerda Vilém Flusser (107) y así como existe ese texto ideal, donde las normas ortográficas, sintácticas y gramaticales han sido empleadas rigurosamente, existe lo que consideramos un buen diseño. De esto se encarga el diseñador de una publicación, profesional en el que recae la tarea de gestionar y organizar la información visual de manera armónica.

En diseño editorial hay dos conceptos clave que involucran a la tipografía, es decir, involucran la manera en que las ideas escritas reciben una forma visual, me refiero a la visibilidad y la legibilidad. El primero hace referencia a la forma del tipo o carácter independiente, mientras que la legibilidad implica la velocidad y facilidad con la que puede leerse un texto. Una letra puede ser visible, pero cuando entra en relación con 
otras, la cuestión de la legibilidad se vuelve relevante. Un buen diseñador sabrá encontrar el equilibrio entre estas dos cuestiones y para eso es clave el conocimiento que se tenga del público objetivo y los procesos de lectura. Adrian Frutiger nos recuerda que los contornos de los caracteres de texto de una lectura continua sufrieron modificaciones bajo la influencia de los diferentes procedimientos de impresión, pero desde los impresores del Renacimiento, hace más de cuatro siglos, la forma fundamental no ha variado (38), en efecto las fuentes que el usuario de un eReader o una tablet puede elegir para su lectura son un conjunto limitado que incluye solo algunas de aquellas letras cuyas características formales son más apropiadas para la lectura continua ya que no agotan o distraen al lector con su forma, paradójicamente, la riqueza de estas letras radica en su "invisibilidad".

Un diseñador siempre intentará que la elección tipográfica sea lo más racional posible, pero no fue siempre así, los primeros impresores intentaron replicar la escritura manuscrita, cada uno diseñó sus propias letras, luego algunos se enfocaron en distribuirlas, llegamos al siglo XX y la elección tipográfica aún tenía mucho que ver con el repertorio de fuentes o matrices disponibles en cada taller, el panorama cambió con la composición digital, donde la gama tipográfica es muy vasta. Finalmente los avances tecnológicos cambiaron el modo de producir libros y también el producto, lo que Pablo Chiuminatto y Renato Verdugo explican del siguiente modo:

Mientras por años la fabricación de libros era optimizada y mejorada gracias a los sistemas computacionales y digitales, el producto seguía siendo el mismo: un libro impreso. Hoy la tecnología ha permitido abrir ese espacio a los lectores, de modo que las interfaces con que diseñadores e impresores trabajan lleguen directamente al lector. En el fondo, reciben aquello que para la imprenta tradicional habría sido parte del proceso como producto final. El pre-libro con el que se trabajaba para que los escritores pudieran modificar, diseñadores paginar y correctores corregir, es lo que -reelaborado, rediseñado y perfeccionado- llega al lector (138).

El lector hoy puede elegir la tipografía como quien elige un par de zapatos. Dentro de las opciones que ofrece Kindle, para la lectura de libros digitales distribuidos por Amazon, hay una que figura bajo el rótulo fuentes del editor, que en la aplicación iBooks tiene su equivalente en la que se denomina original, es la posibilidad de leer con aquella letra que originalmente fue seleccionada por una persona, quien como los cajistas que trabajaron en impresos con tipos móviles, escogió dentro de un abanico de posibilidades. En Kindle está también la posibilidad de seleccionar OpenDyslexic, una fuente creada por el diseñador holandés Christian Boer, con el objetivo de mejorar la experiencia de lectura de las personas con dislexia, es una tipografía con rasgos bien particulares, las letras tienen un mayor espesor en sus partes inferiores lo que provee de una suerte de peso o gravedad a cada letra. La elección de la tipografía hoy puede estar mediada por las necesidades específicas del lector o puede ser instintiva.

Joan Costa, en el epílogo del libro Pensar con imágenes de Enric Jardí, se refiere a la lectura como "un ejercicio óptico, una gimnasia monótona: un movimiento ocular mecánico, repetitivo, meramente instrumental y, por tanto, ajeno a lo que se está leyendo en cada caso. Los ojos se arrastran a lo largo de la línea y siguen en zigzag, de izquierda a derecha, página abajo. Es la tiranía de la línea tipográfica” (123). El hecho de que el 
lector pueda elegir el dispositivo en el que quiere leer, el tipo de letra y el tamaño, a mí me parece un acto liberador. Es liberador para la escritura que desde su invención siempre tendió a una inmaculada fijeza, que la dotó de cierta autoridad en algún momento; es liberador porque ahora no importa tanto la visibilidad sino la legibilidad y esto me recuerda a Otl Aicher cuando nos dice que "hoy tiene poco sentido embellecer el producto, la casa, el cuadro, el libro. Ya no hay objetos singulares cuando debemos ser conscientes de que vivimos en estados y en relaciones" (47). Lo que importa hoy, más que nunca, es la interacción entre el lector y lo que es leído.

En aplicaciones como Kindle el lector puede elegir el ancho de la caja ${ }^{1}$ y el ancho de los párrafos, que en diseño está determinado por el número de caracteres y no a partir del espacio disponible para diseñar. Este principio obedece a la comodidad de la lectura, y para ello se pueden alterar factores como el tamaño de la fuente, la interlínea, el diseño de la letra, etc., El tipógrafo Francisco Gálvez sugiere que los párrafos para textos continuos deben estar compuestos con una media de sesenta caracteres por línea de texto (o también, 7 a 10 palabras), señala que este criterio ayuda a determinar el número de columnas que pueden dividir un texto dentro de una página. Cuando se gira un iPad en posición horizontal, con un texto en Palatino, en el tamaño más pequeño que permite la aplicación Kindle, la cantidad de palabras por fila de texto resulta incómoda, un diseñador estará consciente de que no se ha seleccionado el ancho de párrafo más idóneo, pero si se revisan las opciones de edición, ahora con el dispositivo en esa posición, se ha activado la posibilidad de visualizar el texto en dos columnas. Hoy un texto es como una prenda de vestir elástica, se adaptará a quién lo use, pero también puede resultar incómodo. El lector no está entrenado para tomar decisiones técnicas que tienen que ver con la sensibilidad tipográfica, por lo tanto el riesgo de deformar el texto es una posibilidad, pero hay una valiosa oportunidad para el uso del instinto y la apropiación material del texto como algo vivo, que dialoga con los gustos, actitudes y gestos corporales.

Es habitual que un lector se enfrente a la disyuntiva de elegir entre distintas ediciones impresas de un mismo libro, adquirir una edición de bolsillo o una edición en gran formato con tapa dura no da lo mismo, ya que como señala Lakshmi Bhaskaran "parte del atractivo de una publicación es lo que se siente al tocarla" (6) y eso involucra su materialidad y por supuesto el costo. En la aplicación Archivo abierto $^{2}$ creada por la editorial Fondo de

El tamaño de la caja corresponde al espacio dentro de la página para los textos tratados para la lectura continua; simultáneamente, el espacio sobrante en cada extremo se denomina margen. Francisco Gálvez señala que es interesante comprobar que las dimensiones de la caja han sido acuciosamente estudiadas desde los primeros libros; se buscaron proporciones áureas tanto para los formatos de los libros como para las cajas, con el fin de encontrar un equilibrio entre el formato y la cantidad de texto impreso en cada página.

2 Archivo abierto: 80 años del FCE es una aplicación para dispositivos móviles de descarga gratuita tanto en sistemas operativos iOS y Android. Fue publicada en el año 2014, en el marco de las celebraciones del aniversario número 80 del Fondo de Cultura Económica, de México. Es interesante como en esta app -que reúne parte importante del acervo histórico del FCE, abarcando un total de 160 documentos entre primeras ediciones, fotografías, 
Cultura Económica se explica que "el texto de Guatemala, las líneas de su mano -sus "interiores"- se acomoda de manera distinta en cada una de sus ediciones", haciendo referencia a que un mismo texto lingüístico se despliega y cobra visualidad de formas diversas dependiendo del tamaño del libro y los criterios usados en su composición. En el caso de la impresión con tipos móviles, el texto se adapta al molde tipográfico que se le asigna en imprenta, en el libro digital no, existen tantas ediciones posibles de un texto como individuos que lo leen. Pero no es la primera vez en nuestra historia cultural que se da esta tendencia hacia la personalización de los libros, pensemos en los primeros impresos, que rara vez se vendían encuadernados ${ }^{3}$; se distribuían en rama, es decir impresos y plegados, pero se encuadernaban en las distintas ciudades según la demanda, esto es por encargo del propio comprador, que además, de ese modo encuadernaba a su gusto (Febvre 113) y según sus posibilidades económicas.

Hay libros que originalmente fueron concebidos para ser impresos, pero que hoy en dispositivos móviles funcionan tan bien, que pareciese que fuese ese su lugar natural; Pienso por ejemplo en aquel ingenioso hidalgo que vivía en un lugar de la Mancha y en mi dedo índice tan hábil en la búsqueda de definiciones a cuanta palabra le resulta extraña a mi entendimiento: sayo, morrión, cuitas y tantas otras combinaciones de letras minúsculas que se hicieron eternas gracias a la imprenta y que hoy galopan con renovada fuerza. También pienso en Rayuela, en las letras de Cortázar leo algo que tiene que ver con el hacer: "todo hacer significaba salir de para llegar a, o mover algo para que estuviera aquí y no allí, o entrar en la de al lado, es decir que en todo acto había la admisión de una carencia, de algo no hecho todavía y que era posible hacer...." (Pos. 315*). Eso es lo que considero fascinante, que los libros permitan el hacer. Cortázar se las ingenió con un plan para eso, cada lector debe elegir una forma de leer el libro, hacer la historia siguiendo una ruta establecida en un "tablero de dirección", el libro es un juego que invita a movernos entre lo imprescindible y lo prescindible. Ahora el hacer del libro no involucra mover páginas de papel, orientados por un folio, en Rayuela están los hipervínculos al final de

correspondencia y audio- se hace uso de la tecnología actual para dar cuenta de un pasado que da sentido a las prácticas del presente.

Hoy tenemos acceso a tantas digitalizadas de manuscritos e incunables, al observarlos podemos constatar que siempre estuvo en el espíritu del lector un impulso por manipular el libro, imprimiendo sus gestos en el soporte ya sea como signo de pertenencia, en señal de protesta, desaprobación del contenido o como mero indicio de distracción. Ernst Gombrich se ha interesado por este tipo manifestaciones, en el libro Los usos de las imágenes les dedica un capítulo titulado "Los placeres del aburrimiento", allí identifica dos tipos de juegos que les gusta permitirse a los escribientes, uno derivado de la escritura y el otro de la producción de imágenes.

En los libros con maquetación ajustable, el número de páginas varía de acuerdo a los atributos que cada lector asigne al texto. Por esta razón, las aplicaciones de lectura digital como Kindle asignan posiciones y porcentajes en lugar de números de página. En este caso la posición 315 se encuentra en el capítulo 3, al llegar al 3\% de avance en la lectura de la totalidad del libro. 
cada capítulo, para movernos, pero también se puede prescindir de ellos, como muchas otras cosas que quizás a nadie le importen, como el tamaño de la letra, la cantidad de palabras por página, su separación, el tamaño de la caja, la cantidad de columnas, esas realidades que de tan prescindibles para la lectura se hacen invisibles, como tantas otras cosas, que simplemente no vemos.

\section{BIBLIOGRAFÍA}

Aicher, Otl. Analógico y digital. Trad. Yves Zimmermann. Barcelona: Gustavo Gili, 2001.

Bhaskaran, Lakshmi. ¿Qué es el diseño editorial? Trad. Silvia Guiu Navarro. Barcelona: Index Book, 2006.

Chiuminatto, Pablo y Renato Verdugo. "Del libro impreso al libro digital: discontinuidad tecnológica, nuevos formatos, nuevos hábitos”. Revista Diseña 2013 (5): 136-145.

Cortázar, Julio. Rayuela. Argentina: Penguin Random House, 2016.

Febvre Lucien y Herni-Jean Marin. La aparición del libro. México: Fondo de Cultura Económica, 2005.

Flusser, Vilém. "La sociedad alfanumérica". Revista Austral de Ciencias Sociales 9 (2005): 95-110.

Frutiger, Adrian. En torno a la tipografia. Trad. Anne-Hélène Suárez Girard. Barcelona: Gustavo Gili, 2002.

Gálvez, Francisco. Educación tipográfica. Santiago: UDP, 2004.

Gombrich, Ernst. "Los placeres del aburrimiento: cuatro siglos de garabatos". Los usos de las imágenes. México: Fondo de Cultura Económica, 2003.

Jardí, Enric. Pensar con imágenes. Barcelona: Gustavo Gili, 2012. 